\section{$\mathrm{ADB}$}

White Paper

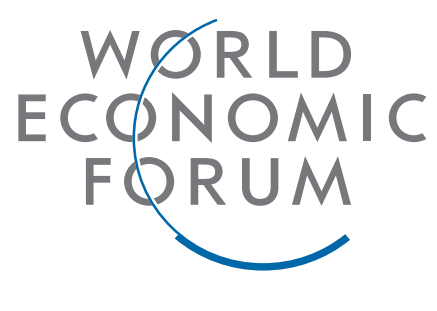

COMMITTED TO

\title{
ASEAN 4.0:
}

What does the Fourth

Industrial Revolution mean

for regional economic

integration? 


\section{Contents}

(C) 2017 World Economic Forum and Asian Development Bank Some rights reserved.

ISBN 978-92-9261-008-1 (print) 978-92-9261-009-8 (electronic)

Publication Stock No. TCS179126-2

DOI: http://dx.doi.org/10.22617/TCS179126-2

World Economic Forum

91-93 route de la Capite

$\mathrm{CH}-1223$ Cologny/Geneva

Switzerland

Tel.: +41 (0)22 8691212

Fax: +41 (0)22 786274

Email: contact@weforum.org

www.weforum.org

Asian Development Bank

6 ADB Avenue, Mandaluyong City

1550 Metro Manila, Philippines

Tel +632632 4444

Fax +632636 2444

www.adb.org

The views expressed in this publication are those of the authors and do not necessarily reflect the views and policies of the Asian Development Bank (ADB) or its Board of Governors or the governments they represent.

ADB does not guarantee the accuracy of the data included in this publication and accepts no responsibility for any consequence of their use. The mention of specific companies or products of manufacturers does not imply that they are endorsed or recommended by ADB in preference to others of a similar nature that are not mentioned.

By making any designation of or reference to a particular territory or geographic area, or by using the term "country" in this document, ADB does not intend to make any judgments as to the legal or other status of any territory or area.

This work is available under the Creative Commons Attribution 3.0 IGO license (CC BY 3.0 IGO) https://creativecommons.org/licenses/by/3.0/ igo/. By using the content of this publication, you agree to be bound by the terms of this license. For attribution, translations, adaptations, and permissions, please read the provisions and terms of use at https://www.adb.org/termsuse\#openaccess

This CC license does not apply to non-ADB and non-WEF copyright materials in this publication. If the material is attributed to another source, please contact the copyright owner or publisher of that source for permission to reproduce it. ADB and WEF cannot be held liable for any claims that arise as a result of your use of the material.

Please contact contact@weforum.org or pubsmarketing@adb.org if you have questions or comments with respect to content, or if you wish to obtain copyright permission for your intended use that does not fall within these terms, or for permission to use the ADB logo. Please contact contact@weforum.org for permission to use the WEF logo.
$4 \quad$ Executive summary

$6 \quad$ 1. Introduction

$7 \quad 2$. What is the Fourth Industrial Revolution?

8 3. What are the key opportunities and challenges of the Fourth Industrial Revolution for ASEAN nations?

$8 \quad 3.1$ Where are the opportunities?

3.2 What are the key challenges?

12 4. How can regional cooperation within ASEAN capture the opportunities and address the challenges of the Fourth Industrial Revolution?

14 5. The Fourth Industrial Revolution and a new approach to regional governance

15 6. A way forward for ASEAN: Suggestions for ASEAN leaders to consider

18 Endnotes 


\section{Project team and advisory committee}

ASEAN 4.0: What does the Fourth Industrial Revolution mean for regional economic integration? is a research report suggested by the World Economic Forum's ASEAN Regional Strategy Group. The report was written and researched jointly by the World Economic Forum and the Asian Development Bank (ADB).

\section{Project team: World Economic Forum}

Justin Wood, Head of Asia Pacific, and Member of the Executive Committee

Thuy Nguyen, Project Lead, Regional Strategies Group

Shailesh Sharda, Community Lead, Regional Strategies Group

Adam Schlosser, Project Lead, Digital Trade and Data Flows

\section{Project team: Asian Development Bank (ADB)}

Jayant Menon, Lead Economist, Trade and Regional Cooperation

Anna Fink, Economist, Regional Cooperation

Arjun Goswami, Technical Advisor, Regional Cooperation and Integration

Sovannaroth Tey, Intern, Regional Cooperation and Integration

\section{Contact}

For feedback or questions: Thuy Nguyen

thuy.nguyen@weforum.org

Sincere thanks go to all involved in this research report for their valuable insights, thought leadership, contribution to this white paper and overall support in shaping the activities of the World Economic Forum in South-East Asia.

\section{Members of the Project Advisory Committee}

Mari Pangestu, Professor of International Economics, University of Indonesia

Nazir Razak, Chairman, CIMB Group, Malaysia

Nick Nash, President, SEA Group, Singapore

Ong Keng Yong, Executive Deputy Chairman, S. Rajaratnam School of International Studies at Nanyang Technological University, Singapore

Rebecca Fatima Sta Maria, Senior Policy Fellow, Economic Research Institute for ASEAN and East Asia, Malaysia

Stephen P. Groff, Vice-President, East Asia, Southeast Asia, and the Pacific, Asian Development Bank, Philippines

\section{Members of the World Economic Forum's ASEAN Regional Strategy Group}

Sun Chanthol, Senior Minister and Minister for Public Works and Transport of Cambodia

Thomas Trikasih Lembong, Chair of Indonesia Investment Coordinating Board, Indonesia

Mari Pangestu, Professor of International Economics, University of Indonesia, Indonesia

James Riady, Chief Executive Officer, Lippo Group, Indonesia

Patrick Walujo, Managing Partner, NorthStar Advisors, Indonesia

Saleumxay Kommasith, Minister of Foreign Affairs of Lao PDR

Tony Fernandes, Group Chief Executive Officer, AirAsia, Malaysia

Mustapa Mohamed, Minister of International Trade and Industry of Malaysia

Azman Mokhtar, Managing Director, Khazanah Nasional, Malaysia

Nazir Razak, Chairman, CIMB Group Holdings, Malaysia

Than Myint, Minister of Commerce of Myanmar

Serge Pun, Chairman, Serge Pun \& Associates, Myanmar

Jaime Augusto Zobel de Ayala, Chairman and Chief Executive Officer, Ayala Corporation, Philippines

Teresita Sy-Coson, Vice-Chair, SM Investments Corporation, Philippines

Ramon Lopez, Secretary of Trade and Industry of the Philippines

Stephen P. Groff, Vice-President for East Asia, Southeast Asia, and the Pacific, ADB, Philippines

Vivian Balakrishnan, Minister for Foreign Affairs and Smart Nation of Singapore

Nick Nash, President, SEA Group, Singapore

George Yeo, Visiting Scholar, Lee Kuan Yew School of Public Policy, Singapore

Thapana Sirivadhanabhakdi, President and Chief Executive Officer, Thai Beverage, Thailand

Apiradi Tantraporn, Minister of Commerce of Thailand

Tevin Vongvanich, Chief Executive Officer, PTT, Thailand

Tran Tuan Anh, Minister of Industry and Trade of Viet Nam

Don Lam, Chief Executive Officer, VinaCapital, Viet Nam 


\section{Executive summary}

This paper focuses on the impact of the Fourth Industrial Revolution on the Association of Southeast Asian Nations (ASEAN). The Fourth Industrial Revolution refers to a set of highly disruptive technologies, such as artificial intelligence $(\mathrm{Al})$, robotics, blockchain and 3D printing, that are transforming social, economic and political systems and putting huge pressure on leaders and policy-makers to respond.

Over the past 50 years, ASEAN has notched up many notable achievements. But the era of the Fourth Industrial Revolution is changing the landscape in significant ways. It is increasingly apparent that the ASEAN organization should consider a new approach to regional policy and governance. The current model, loosely described as "the ASEAN Way", has proven itself to be highly effective. The core principles of this approach to regional relations must remain. But, alongside the ASEAN Way, the region needs a new operating system.

The paper discusses at length the impact of the Fourth Industrial Revolution on ASEAN. It will bring huge benefits, such as empowering SMEs and creating new ways to connect citizens to healthcare. Equally, it will bring tremendous challenges, such as deep disruption to jobs as $\mathrm{Al}$ and advanced robotics undermine both manufacturing and services jobs.

The paper also explains why ASEAN must adopt a regional approach to navigating the Fourth Industrial Revolution. Yes, national-level policies are critical, and ASEAN nations are pursuing these diligently, such as Thailand 4.0 and Singapore's Smart Nation initiative. But the technologies of the Fourth Industrial Revolution do not recognize national borders. If ASEAN leaders do not think regionally, they will miss out on opportunities and fail to address growing challenges.

The Fourth Industrial Revolution also calls for a new way of formulating policy and regulation. The speed of change under the revolution is accelerating, and the old ways of crafting policy, especially cross-border policy, are too slow, too backward-looking and too rigid. Instead, governance and regulation need to become more agile, faster, more iterative and experimental.

In its current form, the ASEAN organization may struggle in this new world. Indeed, it is already facing challenges in achieving many of its current goals, such as those for creation of the ASEAN Economic Community. This paper concludes with some concrete suggestions for how ASEAN leaders could rethink their approach to regional interaction under the ASEAN Secretariat.

\section{Seven suggestions for ASEAN leaders}

\author{
1. ASEAN Secretariat to become a "platform \\ organization"
}

Regional integration, particularly in the era of the Fourth Industrial Revolution, is highly complex. Every industry standard, every investment rule, every technical agreement that is addressed requires not only significant expertise but also considerable time and effort. Overseeing this complexity, and doing it at the speed of the Fourth Industrial Revolution, demands a new approach to organizing regional integration efforts.

One important idea is for the ASEAN Secretariat to consider becoming more of a "platform organization". This means creating an ecosystem upon which multistakeholder groups of experts do the heavy lifting of integration, with the Secretariat acting as the convener and governor of their activities.

A useful analogy is the Apple iOS or Android operating systems used on smartphones. In both cases, Apple and Google create the ecosystem upon which third parties software developers - are the main actors. Neither Apple nor Google are directly involved in developing new apps. Instead, their role is to govern the ecosystem and to make sure it runs smoothly, with all actors adhering to the rules of the platform.

In the context of ASEAN, the Secretariat would design and run the "operating system for regional integration". Third parties - multistakeholder groups of experts - would do the work of designing and formulating new standards, policies and regulations for integration. The role of the Secretariat would be to ensure that all the various integration projects running on its "operating system" were well governed and were conducted in the right manner.

In many senses, the ASEAN Secretariat already functions as a platform organization. But the idea would be to formalize and upgrade the operating system so that the "app developers" (the multistakeholder groups working on integration projects) could function more effectively. For the Secretariat, this would mean a shift in how it works. On the one hand, it would play a stronger role in running the "operating system for regional integration", through things such as convening and governing working groups. On the other hand, it would play a reduced role in producing the actual content of integration (the suggestions for new standards and regulations), which would be produced by the working groups. 
Ideas for developing new "apps" or integration projects would need to be endorsed by the ASEAN member states. But, once endorsed, a working group would be convened on the platform to do the work of crafting the regulations. The ASEAN Secretariat would oversee the formation of the working group and ensure that the group followed agreed processes for developing regulations.

This platform model is not intended in any way to undermine the sovereignty of ASEAN nations. Any proposals for new regulations or standards would still need to be ratified at a national level before they became law.

Adopting a platform approach would require significant changes to the modus operandi of the Secretariat. As such, it would make sense to adopt a stepped approach, whereby certain regulatory issues, such as those governing e-payments, are experimented with first, adopting a "sandbox" approach. If the model is proven to be effective, the approach could be adopted more broadly.

\section{Delegate key activities to affiliated functional bodies}

Extending the idea of ASEAN as a platform organization, the Secretariat could also consider delegating more functions to affiliated third-party groups. These groups or institutions would operate on the platform in a more independent fashion. This would allow ASEAN to maintain oversight while also benefiting from a larger ecosystem of institutions, which will be critical in managing the sheer scale of engagement and implementation that will be required. One notable example is the ASEAN Macroeconomic Research Office (AMRO), which is responsible for managing the region's financial safety net under the Chiang Mai Initiative Multilateralization.

\section{Shift from long-term blueprints to rolling three-year plans}

At present, ASEAN invests considerable effort in developing a strong long-term vision for regional integration with documents such as the ASEAN Economic Community Blueprint 2025. Arguably, however, because the Fourth Industrial Revolution is characterized by rapid, non-linear change, plans such as these quickly become outdated. Under the Fourth Industrial Revolution it is advisable not to attempt to forecast the future because most forecasts are likely to be wrong. Rather, it is important to be agile and allow for course correction. ASEAN could, therefore, consider supporting its overarching goals with rolling three-year strategies that are revisited and revised frequently.

\section{Ask the people: Democratize and decentralize}

If ASEAN is truly to benefit from the widespread expertise in its societies, it should consider increasing its openness to their direct engagement in policy creation. The founding vision of ASEAN was to create an organization that is owned by the people of ASEAN and run for their benefit. The Fourth Industrial Revolution could help this vision to become reality. As internet and smartphone penetration deepens across ASEAN, there is substantial opportunity to make ASEAN policy formulation more inclusive. Dedicated portals could be established to gain direct feedback from ASEAN citizens and experts and to crowdsource ideas.

\section{Multi-country test beds}

A pan-ASEAN platform could be established that would nurture multi-country regulatory experiments and crossborder innovation hubs. An initiative of this kind was set up in Europe in March 2017, called the European Platform of National Initiatives (EPNI). The goal of EPNI is to help European industries respond and stay abreast of the Fourth Industrial Revolution by linking national initiatives to create multi-country test beds and "sandboxes", where regulations can be tested in different regulatory contexts to help a rapid roll-out across the wider European Union.

\section{A new staffing model for the Secretariat}

Running the "operating system" for regional integration would require the ASEAN Secretariat to think in new ways. The key to success is operational or execution excellence. In particular, the Secretariat would need to hire staff capable of running a platform model effectively, and who are well versed in managing the new tools of the Fourth Industrial Revolution, such as new systems of communication, new mechanisms for virtual collaboration, and new tools for gathering feedback and ideas.

Alongside a shift in skills, ASEAN leaders could consider a new approach to the recruitment of staff, with workers hired for their skills on a permanent basis, rather than through "appointment", based on rotation among ASEAN nations. In a similar development, the Secretariat could consider appointing a permanent "CEO" type of leader, hired for his or her experience in crafting regulation and policy, and with a strong record of execution.

\section{A new funding model for the Secretariat}

To recruit the right staff, in the right number, and to build the right systems to drive integration, the ASEAN Secretariat will need more funding. The current funding level of roughly $\$ 20$ million a year is not enough. ADB estimates that, by 2030 , the ASEAN Secretariat will need an annual budget of $\$ 220$ million to manage the ASEAN Community effectively. One possible model might be that used by the United Nations, with contributions linked to the economic size of countries. Naturally, if funding is increased, it creates concerns of a concurrent rise in bureaucracy and waste. These concerns could be addressed by redesigning the ASEAN Secretariat along the lines suggested in this paper. 


\section{Introduction}

The 50th anniversary of the Association of the Southeast Asian Nations (ASEAN) in 2017 is an important moment to reflect both on the achievements of the organization as well as the challenges that lie ahead.

Over the past 50 years, ASEAN has notched up many notable successes. Chief among them has been the creation of a community committed to peace. Established in 1967 between Indonesia, Malaysia, the Philippines, Singapore and Thailand, the grouping has added five new members: Brunei Darussalam, Cambodia, Lao PDR, Myanmar and Viet Nam. This expansion has turned a region previously dogged with conflict into one of harmonious coexistence. Mahbubani and Sng (2017) argue that ASEAN is "more deserving of the next Nobel Peace Prize than any other person or institution today"1.

At the core of this community lies a unique approach to regional governance and cooperation. The so-called "ASEAN Way" is a commitment to the protection of national sovereignty, to non-interference in the domestic matters of fellow countries, to making decisions based on consensus building, and to an operating style between leaders that is informal. Alongside the ASEAN Way, member nations have also pursued a policy of "open regionalism" that has served as a catalyst for wider cohesion across the Asia Pacific².

The ASEAN peace dividend, combined with trade and other reforms within the bloc, has stimulated strong economic growth. In the past decade, regional GDP has doubled from \$1.3 trillion (2007) to \$2.6 trillion (2016). The incidence of poverty has fallen dramatically and prosperity looks set to keep rising: the population with an income of more than $\$ 5,000$ a year is estimated to grow from 300 million in 2015 to 400 million in 2020, making ASEAN one of the world's most important emerging consumer markets ${ }^{3}$.

The success of ASEAN has allowed the organization to evolve and expand its mandate beyond regional security. In 2015, ASEAN established the ASEAN Economic Community (AEC), which ushered in a bold agenda for enhanced economic integration.

But alongside its many successes, ASEAN faces considerable challenges, from rising inequality to rapid urbanization and climate change. Arguably the most momentous challenges will come from the spread of the Fourth Industrial Revolution. A set of highly disruptive technologies, such as artificial intelligence (Al), robotics, blockchain and 3D printing, is transforming social, economic and political systems in often unpredictable ways, putting huge pressure on leaders and policy-makers to respond. Earlier this year, Jack Ma, founder and chairman of Alibaba, a Chinese e-commerce giant, noted that the
Fourth Industrial Revolution "will see much more pain than happiness in the next 30 years".

The transformative impact of this revolution will demand that countries think deeply about their policies and priorities at a national scale. Many ASEAN governments are well aware of this need and have launched national responses, such as Thailand 4.0 and Singapore's Smart Nation initiative.

Importantly, however, some of the greatest impacts of the Fourth Industrial Revolution will play out not at a national scale but at the regional scale. The nature of cross-border relations and economic interaction will be revolutionized. It will not be enough to think only about a national response. In the years ahead, regional organizations like ASEAN will be called upon ever more heavily to help steer and shape these historic transformations. And yet, given the accelerating speed and breadth of technological change, shaping regional policy is growing ever harder. It means that ASEAN and organizations like it will need to reimagine and redesign the way they manage regional governance.

While acknowledging the huge success of ASEAN over the past 50 years, this paper looks to the future. It considers what impact the Fourth Industrial Revolution will have on the region and how ASEAN can continue to thrive. Some of the key questions include:

- What opportunities and challenges does the Fourth Industrial Revolution create for the nations of ASEAN?

- What role should regional cooperation play in capturing the opportunities and addressing the challenges?

- How should regional organizations, such as ASEAN, respond to the changing landscape that the Fourth Industrial Revolution brings?

- What suggestions should the leaders of ASEAN consider for reforming their regional organization to be as effective as possible in this new era?

The paper is organized into six sections. Section 2 defines the Fourth Industrial Revolution and how it differs from past industrial revolutions. Section 3 then takes a broad look at the opportunities and challenges that the Fourth Industrial Revolution poses for ASEAN member countries. In Section 4, the paper shows the pressing need for regional cooperation in addressing these opportunities and challenges. Section 5 argues that, in addition to deeper regional cooperation, ASEAN leaders must also adopt a new approach to organizing their regional cooperation and governance. Finally, Section 6 sets out key ideas for ASEAN leaders to consider on how the ASEAN organization could evolve to address the Fourth Industrial Revolution. 


\section{What is the Fourth Industrial Revolution?}

The term "revolution" denotes abrupt and radical change. Throughout history, new breakthrough technologies have brought about many such periods of significant, non-linear change that profoundly alter economic systems and social structures. The arrival of the Fourth Industrial Revolution is a new period of exactly this type of deep, transformative change. ${ }^{5}$

Looking back, the first profound shift for human civilization came with the agrarian revolution 10,000 years ago. The domestication of animals, coupled with new farming technologies, improved food production, spurred dramatic population growth and led to the rise of fixed settlements.

This agrarian revolution was followed around 1760 with the First Industrial Revolution, driven by the rise of steam power, railways and mechanized forms of production. The Second Industrial Revolution took hold in 1890 with the rise of electricity and new approaches to manufacturing based on assembly lines and mass production. The Third Industrial Revolution emerged in the 1960s with the rise of semiconductors and the spread of computers and the internet.

Today, we face a Fourth Industrial Revolution. Building on the digital technologies of the Third Industrial Revolution, it is powered by a wide range of new breakthroughs not only in the digital realm (such as artificial intelligence) but also in the physical realm (new materials), as well as the biological realm (bio-engineering). (See Box 1.) These new technologies are revolutionary due to the speed, breadth and depth of the anticipated change they will bring.

\section{Box 1: Fourth Industrial Revolution technologies}

- Artificial intelligence and machine learning

- Advanced robotics and new forms of automation

- Ubiquitous mobile internet

- Sensors and the internet of things

- Blockchain and distributed ledgers

- 3D printing

- Autonomous vehicles, such as cars and drones

- New materials, such as graphene

- Genetic advances, bio-engineering, personalized and precision medicine

- New energy sources and storage technologies

- Quantum computing
- Unprecedented breadth and depth: The Fourth Industrial Revolution will change everything. The new technologies, and the interaction between them, will offer new ways to create and consume, will transform how we deliver and access public services, and will enable new ways to communicate and govern. Almost every aspect of our lives will be touched: jobs, business models, industrial structures, social interactions, systems of governance. The Fourth Industrial Revolution will even challenge the very concept of what it means to be human.

- Accelerating pace of change. New technologies are emerging faster, being adopted more quickly and delivering greater impact than ever before. Fixed-line telephones, first developed in 1878, took 75 years to reach 100 million users. Mobile phones, which emerged in 1979, took 16 years to reach 100 million users. The internet, which was launched to the public in 1990, took six years to reach 100 million users. The Apple App Store, unveiled in 2008, took just three years to reach 100 million users $^{6}$.

Many factors underpin the accelerating pace of change. For a start, the number of scientists and engineers graduating each year is rising rapidly: in 1998, the countries of the Organisation for Economic Co-operation and Development (OECD) produced 158,000 PhDs, but in 2014 that number had grown to 266,0007. What's more, machine learning and big data analytics mean the process of discovery and analysis often no longer requires human agency. The processing power of computer chips (from the Third Industrial Revolution) has increased by 1 trillion times over the past 50 years, and quantum computing has the potential to perform tasks that are barely conceivable today. Equally important, digital networks allow products, services, ideas and knowledge to scale and reach critical mass more quickly than ever before. One consequence of all this change is that the impact of the Fourth Industrial Revolution will be extremely hard to predict. 


\section{What are the key opportunities and challenges of the Fourth Industrial Revolution for ASEAN nations?}

The countries of ASEAN are politically, economically and socially diverse. However, the Fourth Industrial Revolution will bring many common opportunities and challenges.

\subsection{Where are the key opportunities?}

- Increasing wealth: Increased productivity from "disruptive technologies" could unleash an additional $\$ 220$ billion- $\$ 625$ billion in annual economic impact in ASEAN by $2030^{\circ}$. It will also provide huge value for individuals not captured by traditional measures. One hundred years ago, not even the richest person in the world could buy a TV, an air ticket, contact lenses, or antibiotics. Today, these things are within the reach of ever more people. The Fourth Industrial Revolution will massively expand consumer choice, lower costs and raise quality, all of which will be equally hard to value.

- A powerful force for economic inclusion: Fourth Industrial Revolution technologies will create new ways for citizens to connect to each other, to trade with each other, and to access services that are currently not available. In Viet Nam, the Philippines and Myanmar, a third or less of the population have a bank account ${ }^{9}$. Under the Fourth Industrial Revolution, citizens will gain access to new sources of information, (for example, news and market prices), new forms of education (such as online courses and virtual classrooms), new healthcare (for example, telemedicine powered by smartphones linked to diagnostic pills) and new financial services. The result could be much more inclusive forms of economic growth.

- Empowering SMEs: Small and medium enterprises (SMEs) are the backbone of ASEAN economies. Between $89 \%$ and $99 \%$ of enterprises within ASEAN are SMEs and they provide between 52\% and 97\% of employment in member states. They're also an important source of innovation. But many SMEs are limited in their ability to grow because of lack of access to finance, business services and information, and constrained access to markets beyond their immediate neighbourhood. However, the rise of digital marketplaces and online services can empower SMEs to trade in ways unimaginable even a few years ago, connecting them to giant regional markets rather than just local customers. Technologies such as blockchain will revolutionize payments and logistics, enabling small firms to interact on a trusted basis despite never having met each other. The Fourth Industrial Revolution thus promises to unleash a world of micro-transactions. At present, the value of e-commerce in ASEAN stands at $\$ 9$ billion, or about $\$ 14$ per person. In the People's Republic of China, by comparison, the value is $\$ 426$ billion, or $\$ 327$ per person, which illustrates the size of the potential ${ }^{10}$. (See Box 2.)

\section{Box 2: Unleashing the power of SMEs}

Pujo Nugroho, an Indonesian small business owner, started Borneoethnic in Kalimantan in 2009 selling locally sourced and crafted rattan bags. At first, he sold mostly to his local community.

In June 2016, however, he joined Shoppee, an online marketplace that enabled him to reach new customers much further afield. The move brought a big increase in orders. Over the course of half a year, his revenue rose from IDR 3 million-IDR 5 million a month to more than IDR 8.9 million a month. As a result, he has increased his full-time employees from two to seven.

- Opportunities for leapfrogging: Technologies of the Fourth Industrial Revolution create the opportunity for developing countries to bypass traditional phases of industrial development. Mobile phones, for example, have already reduced the need for countries to lay expensive fixed landlines. Online and mobile banking is reducing the need to build networks of physical bank branches. While the infrastructure needs of ASEAN remain formidable, developments driven by the Fourth Industrial Revolution suggest they could be lower, and certainly different, than they would otherwise be. Localized renewable energy production, such as solar power coupled with new battery storage technology, could reduce the need for investing in expensive power distribution networks. Drones could help to deliver lightweight, high-value goods such as medical supplies to remote regions with poor transport infrastructure. 
While drones will not remove the need to build roads for the transport of heavy goods and people, they do offer the opportunity to design transport infrastructure in new ways and to reduce the need for "last-mile" road connectivity. Indeed, with clever policies, ASEAN could become a global leader in drone delivery and other emerging drone applications through smart, regionally harmonized regulation.

- Connecting the unconnected: Some ASEAN nations, notably Indonesia, the Philippines and Malaysia, are archipelagic and physical connectivity has long been a concern for economic development. Equally, some ASEAN countries have large rural populations in remote areas that have yet to benefit from the technologies of the first and second industrial revolutions. In Cambodia and Myanmar, only about half of the population has access to electricity ${ }^{11}$. The Fourth Industrial Revolution offers new possibilities for developing distributed structures for services that can overcome geographical limitations. For example, new renewable energy technologies that are generated locally rather than in centralized power plants can link people to electricity. 3D printing will enable people to manufacture products at small scale as required, subject to the availability of raw materials, right next to where they are needed, and so overcome resistance by distributors to serve remote regions. New initiatives can bring high-speed internet to isolated communities. (See Box 3.) The required investment in infrastructure will change substantially. Investments in high-speed broadband, 3D printers and local power hubs could provide a faster way to connect people than investments in roads, shipping and electricity grids. Drone delivery also offers an opportunity to provide improved access to vital supplies, such as vaccines, to remote areas. Given the high cost of moving goods around archipelagic nations, automated aerial logistics may be particularly advantageous in the ASEAN context.

\section{Box 3: Project Loon Indonesia}

Project Loon is a global initiative to provide internet access to remote areas. Powered by solar and controlled remotely, the balloons bounce signals from telecom companies along a continuous string of balloons and blanket otherwise unconnected areas. In Indonesia, only a third of the population has access to the internet. In 2015, Project Loon partnered with XL Axiata, Indosat and Telkomsel to test the technology and bring internet access to Indonesia's remote islands.

- $\quad$ Fighting congestion and road deaths: In SouthEast Asia, 316,000 people die every year from traffic accidents. The Japanese International Cooperation Agency estimates that the Philippines will lose PHP 6 billion every day by 2030 if worsening traffic congestion is not resolved and this is a familiar story across the region ${ }^{12}$. The Fourth Industrial Revolution offers a number of solutions. At a simple level, crowdsourcing of traffic conditions, whereby road users provide updates, are already providing solutions to ease congested roads. More significantly, self-driving vehicles offer the potential to increase safety and security on the roads, subject to proper testing and regulations. "Smart" urban transport systems, that combine multiple technologies and integrate them into a connected system, will provide more efficient options for getting around cities and for reducing road deaths, congestion and pollution. (See Box 4.)

\section{Box 4: Singapore Smart Nation}

Singapore introduced its "Smart Mobility 2030" strategic plan in 2014. The plan focuses on implementing innovative and sustainable smart mobility solutions. A number of initiatives have been launched as part of the plan.

- Singapore has allowed trials of on-demand autonomous vehicles (ODAV) as a mobility service in Singapore since August 2016. Commercial ODAV services may be rolled out across Singapore in 2018.

- $\quad$ The first electric vehicle-sharing programme in Singapore will be launched in December 2017, with 30 charging stations and 80 electric cars being rolled out progressively.

- $\quad$ Autonomous buses, which will be 12 metres long with a maximum speed of $60 \mathrm{~km} / \mathrm{h}$ and can seat 40 people, may run on fixed and scheduled routes in Singapore in 2020.

- $\quad$ Numerous self-driving vehicles are in operation in controlled areas, such as autonomous golf carts at Nanyang Technological University.

- Improving environmental management: Recent calculations suggest that $40 \%$ of the land in six ASEAN countries is suffering from "severe or very severe" human-induced degradation ${ }^{13}$. With economic growth projected to grow at 8\% a year for the next six years (IMF dollar terms projections), pressure on the environment will increase substantially. Artificial intelligence, drones and remote sensing offer opportunities to monitor fisheries and forestry activities much more effectively. Irrigation systems can be automated and blockchain can be used to manage water allocations.

- $\quad$ Transforming agriculture: Many ASEAN countries have large agricultural sectors and the Fourth Industrial Revolution is likely to impact farming positively. In the short term, the impact of connecting farmers to the internet has already brought well-documented improvements to farmer productivity, profitability and sustainability. Smartphones give farmers better access to market prices, weather information, and knowledge about soil, seeds and fertilizer. Smartphones may also enable a "sharing economy" to take hold, whereby farmers who can't afford to buy mechanical equipment can rent it by the hour from other farmers by accessing online sharing sites. In India, Mahindra \& Mahindra, an equipment maker, has set up a platform of this type called Trringo ${ }^{14}$. 
The Fourth Industrial Revolution will also improve the traceability of products, and thereby reduce the risks of food being contaminated. E-payments will enable farmers to reduce transactions costs. New logistics applications are enabling more efficient utilization of trucking services into and out of rural areas. Technology is also starting to overcome the critical constraint of agricultural finance by enabling suppliers to use new credit-scoring technologies. (See Box 5.) In the longer term, as farming is primarily a biological process, new technology will enable the easier creation of elite genetic material (seeds, plants and livestock) and the increasing usage of microbiology in farming systems.

\section{Box 5: Social media payback}

Lenddo, which was launched in the Philippines in 2011, is bringing a revolutionary approach to assessing the creditworthiness of the emerging middle classes. In many countries, the traditional data used to make credit scores that allow small business owners and individuals to borrow money are not well developed.

Given this absence of data, Lenddo has devised new techniques that use a person's online activity on sites such as Facebook, Google, Yahoo and Twitter. Clever algorithms and data analytics have enabled the firm not only to prove the identity of individuals in the absence of passports or driving licences but also to assess their likelihood to repay a loan.

Today, Lenddo operates in many countries, including Thailand and Cambodia.

- Improved health and healthcare: This paper has already mentioned how the Fourth Industrial Revolution will bring new business models for delivering health services (such as telemedicine). But more fundamentally, it will also enable doctors to collect and understand genetic, environmental and behavioural data on their patients. This will enable the identification of preventive actions, treatments or cures that are increasingly tailored to a specific individual or community (rather than using medicines that are "one size fits all"). Sometimes referred to as "precision medicine", this will not only improve medical treatment but also potentially lower the costs of providing health services by reducing money spent on inappropriate medicines.

- Upgrading disaster preparedness: South-East Asia is particularly vulnerable to the impact of climate change given the continued reliance on agriculture by much of the population, heavily populated coastlines and continued incidence of poverty. However, the region has huge potential to contribute to climate change mitigation. Blockchain technologies allow for costeffective and transparent carbon emissions tracking and the establishment of carbon markets such as the one being established in the People's Republic of China ${ }^{15}$. Equally, the technologies can provide new ways of preparing for disasters and delivering aid to the worstaffected regions.

\subsection{What are the challenges?}

- Job losses and disruption: Artificial intelligence and robotics are rapidly increasing the jobs that machines can perform better and faster than people. While this may reduce costs and raise productivity, it will also threaten jobs, and some members of ASEAN will be more affected than others. The immediate threats are to low-skilled, repetitive jobs (such as assembly line workers), but services jobs are also at risk, threatening to undermine regional success stories such as the rise of the business-process outsourcing sector in the Philippines,

Every industrial revolution creates fears over job losses. In the past, however, new technologies generally led to more jobs being created through the growth of new industries. But under the Fourth Industrial Revolution, the outlook is less positive. The International Labour Organization estimates that $56 \%$ of jobs in five ASEAN countries (Cambodia, Indonesia, Viet Nam, Thailand and the Philippines) are at high risk of automation in the next few decades ${ }^{16}$. At the same time as jobs are at rising risk of automation, the workforce in ASEAN is forecast to grow by 11,000 new workers every day for the next 15 years $^{17}$. In the short term at least, it is likely that unemployment will increase. This could lead to higher numbers of economic migrants within ASEAN and increasing inequality. Retraining and skills development may cushion the impact of automation, but they will not prevent deep disruption.

- Inequality and political instability: Economic convergence between ASEAN's developed and less-developed economies has shown promising trends in the past two decades. In 1997, Singapore's GDP was 57 times that of Lao PDR. In 2016 this had been reduced to less than 19 times $^{18}$. However, this promising trend has been accompanied by growing inequality within countries. The impact of the Fourth Industrial Revolution has the potential to accelerate returns to talent and knowledge. This could slow down - or even reverse - convergence between countries and would widen inequality within countries. Noninclusive growth has the potential to increase social and political instability within countries and undermine popular support - and indeed trust - in greater regional integration.

- The end of traditional "Factory Asia": Industrialization within many Asian countries has been based on the supply of relatively low-cost and low-skilled labour attracting foreign investment. But artificial intelligence and robotics will decrease the competitiveness of lowcost and low-skilled labour. Equally, 3D printing will transform the nature of manufacturing. Today, many goods are made at centralized locations operating at scale and producing standardized products. In future, 3D printing may mean that products are produced locally, next to demand, on a highly customized basis. For example, Caterpillar and John Deere, two American producers of construction and agricultural equipment, are already effectively moving their warehouses to an online cloud. Digital designs are downloaded to different 
locations and printed to order. This could lead to the reshoring of production in many industries back to high labour-cost countries and reduce the attractiveness of foreign investment in ASEAN's manufacturing industries. Rapid movement towards knowledge-based economies will be required for ASEAN to remain competitive.

- Concentration of market power by global giants: While the Fourth Industrial Revolution promises to be empowering for ASEAN's SMEs, it may create difficulties for larger ASEAN businesses. This is especially true for "platform businesses" - the types of company that require scale to be competitive, such as banks and online marketplaces. Under the Fourth Industrial Revolution, the spread of digital networks means that the economics of platform businesses no longer experience diminishing returns to scale. Adding an additional customer (or user) has almost zero marginal cost and instead delivers ever greater value through the impact of network effects. This phenomenon is already well documented. For example, globally, Google currently controls $90 \%$ of search advertising, Facebook controls $77 \%$ of mobile social traffic and Amazon has $75 \%$ of the e-book market. While platform businesses are empowering for their users, they make the emergence of ASEAN homegrown platform businesses deeply challenging because they lack the scale to compete with non-ASEAN competitors.

- More exposure and vulnerability to cyberattacks: As ever more devices, sensors and machines are connected to the internet, the potential for damage and disruption from cyberattacks is rising significantly. And yet, governments in ASEAN have not invested the time to develop proper cybersecurity measures, policy and law, neither at the national nor at the regional level. The Center for Strategic and International Studies estimates that the likely annual cost to the global economy from cybercrime is between $\$ 375$ billion and $\$ 575$ billion $^{19}$. 


\section{How can regional cooperation within ASEAN capture the opportunities and address the challenges of the Fourth Industrial Revolution?}

The benefits of regional cooperation are well understood by ASEAN nations. Deeper integration allows businesses to access larger markets and thereby become more efficient. It lets employers source workers and skills from a larger pool. It creates opportunities for cross-fertilization of ideas, transfer of knowledge, and for new forms of collaboration that connect different resources in complementary ways. It helps manage cross-boundary issues such as pollution and transnational crime.

But under the Fourth Industrial Revolution, the need for regional cooperation, and the benefits that flow from deeper regional collaboration, is significantly heightened. Indeed, it is well documented that the Fourth Industrial Revolution does not recognize national borders. The following examples show how a regional approach to addressing the Fourth Industrial Revolution will help ASEAN both capture the opportunities and manage the risks.

- Data sharing: Data is the foundation of the Fourth Industrial Revolution - all of the new technologies are built on it. Of particular importance is the ability to transfer and access data across borders. Individuals, companies and governments will increasingly rely on the ability to move, process and store data throughout ASEAN to provide the services and reap the benefits of the Fourth Industrial Revolution.

Consider some of the business models powered by sensors and the internet of things. The performance of machines such as jet engines and earth-moving equipment can be monitored remotely and their settings adjusted in real time to improve performance and efficiency. Combining different types of data, and reusing existing data, allows for an exponential increase in the creation of economic and social benefits. Conversely, any attempts to lock data away and to erect barriers to accessing data will reduce the ability of companies and individuals to thrive in the new era. ASEAN, therefore, must think deeply about how it can encourage data to flow without friction and without barriers between nations.
But as well as bringing giant benefits, the cross-border flow of data may also bring challenges, particularly related to personal and sensitive information, such as health records or financial transactions. Issues of security, privacy and intellectual property rights are of paramount concern. However, the security and privacy of data do not depend on the physical location of servers. Rather, they depend on the protocols and rules that exist in the places where the data is accessed, used and stored. As such, ASEAN nations need to work collaboratively on crafting rules and regulations that govern how data can flow across borders and under what conditions. Countries that block cross-border data flows in the name of issues such as security and privacy could end up stifling their economies.

- $\quad$ Trade and manufacturing: The character of trade is shifting away from physical goods towards virtual goods. Media products such as books, music and movies have already made this transition. But even products such as engines and spare parts are becoming more virtual in character. Rather than importing and exporting finished goods, companies may instead sell blueprints and designs, with customers using 3D printers to manufacture the goods at their own locations. Today, ships and offshore oilrigs already use 3D printers to manufacture spare parts onboard. These trends, if they gather momentum, will have profound implications for industrial policy in ASEAN. Important questions will emerge around who sets industrial standards and safety regulations and how they are enforced. If a customer in one ASEAN country sources a virtual product from another country, prints it locally and then suffers an injury, who is liable? And how can they seek legal redress?

- Service standards: Cross-border trade is shifting in other important ways too, notably with the rise of trade in services relative to goods. Take healthcare. Citizens in Cambodia could access their healthcare from centres of medical excellence in the Philippines using smartphones (coupled with technologies such as diagnostic pills that send medical information via Bluetooth to the user's 
smartphone). These cloud services promise giant opportunities to bring much-needed services to ASEAN citizens, especially in remote areas, at much more affordable prices. For the economics to work, however, the services must be provided at scale across the region and not at just a national level. This means not only allowing sensitive data (for example, health data) to flow across borders but also to have regional standards governing healthcare services. There is also the need to harmonize rules on market access and to make the rules as transparent as possible.

- Harmonized business environment: To succeed in the era of the Fourth Industrial Revolution, ASEAN's platform and infrastructure businesses (such as banks, payment firms, online marketplaces, logistics providers) will need to operate at regional scale. Currently, many ASEAN firms operate in relatively small domestic markets. This prevents them from achieving economies of scale and the benefits of network affects. Harmonizing laws and regulations between countries, and promoting open access to ASEAN businesses, will be essential to addressing this. Without harmonizing business regulations, homegrown ASEAN companies risk losing out to larger rivals from outside the region. These larger rivals have grown up in naturally large domestic markets such as the United States or the People's Republic of China and have used their homegrown scale to invest in innovation that potentially enables them to out-compete ASEAN rivals.

- Rethinking fiscal policy: As products become virtual, and as services move online and are delivered remotely, it changes the ability of government to levy and collect taxes. Given the rise of cross-border commerce linked to digital platforms, governments will need to work with each other on defining what tax rules will govern regional commercial interaction.

- Innovation incubators: Innovative SMEs and startups will be critical to capturing the opportunities of the Fourth Industrial Revolution. Many ASEAN countries already have innovation hubs and incubators at a national level. However, to be competitive, new businesses will need to operate at scale and to reach scale rapidly. ASEAN leaders should think about how to connect national incubators into regional networks and to overlay regional business and financial support services to help SMEs operate across ASEAN.

These regional networks would open doors to new opportunities, nurture the cross-fertilization of ideas between cultures and communities, and support the exploration of complementarities between countries.

- Regional education networks: Countering job losses and disruption from the Fourth Industrial Revolution will require a transformation of education. The skills needed to thrive will centre not only on technical capabilities but also on creativity and innovative problem-solving. What's more, given the accelerating pace of change in the job market, workers must expect to have several "careers" rather than just one, which calls for a deep commitment to adult training and lifelong learning, not just early-life education. Much of the response from policy-makers will play out at the national level, but there is an important regional dimension too. Online education will give students access to education opportunities beyond their borders. Equally, the expansion of existing credit-transfer systems between ASEAN universities would help build cross-border personal and professional networks which will be crucial for the worker of tomorrow.

- Reducing barriers to labour mobility: To grasp the opportunities presented by the Fourth Industrial Revolution, countries will need access to pools of human capital with new skills, such as data scientists, IT systems managers and software coders. Reducing barriers to the mobility of skilled workers in the region would help to meet this demand ${ }^{20}$. This may call for an expansion of existing mutual recognition agreements (MRAs) for professional qualifications to cover new occupations. Existing commitments on harmonizing and streamlining employment visas will be critical and consideration could be given to programmes that help workers overcome language and cultural barriers to movement. If labour is prevented from moving across the region, the benefits of the Fourth Industrial Revolution may not be evenly shared and regional inequality may rise.

- Support a regional "human cloud": The world is moving to a model where many individuals no longer work for companies but are self-employed contractors. Sometimes called the "human cloud", the picture is one where individuals compete online to fulfil specific tasks, such as design projects or accounting services. Also known as the "gig economy", it has the potential to empower millions of individuals by giving them access to a world of opportunity that has previously not been available. But such jobs will only come about with a regional approach to data management that allows cross-border interaction. Just as important will be regional agreements on taxation and social protection.

All of the issues listed here will demand a regional approach to governance, policy and regulation. But underlying all of these challenges sit broader questions that ASEAN leaders must consider. These questions centre on the importance of "values". All new technologies have human values baked into them to some degree. For example, what does privacy mean in a world full of drones? Should artificial intelligence be able to make life-and-death decisions? How much inequality is acceptable?

Answering these questions will require regional leaders to assess the common values shared by a highly diverse group of cultures and to craft protocols that ensure these shared values are universally applied in an ASEAN context. 


\section{The Fourth Industrial Revolution and a new approach to regional governance}

The Fourth Industrial Revolution will not only affect the priorities and issues for regional integration within ASEAN but also will require a new approach to how these policies are created and implemented. Given the significance of the Fourth Industrial Revolution, and the speed at which it is unfolding, it will be critical for ASEAN leaders to think creatively about how they can upgrade the process of crafting policy, setting standards and writing regulation at a regional scale. If they do not, the region may well find itself on the wrong side of this moment of global reset. Rather than thriving, the region may find itself being left behind.

The traditional models of crafting policy, regulation and standards have often been relatively linear, time-consuming and top-down in their approach. Today, the imperatives of regional governance demand a different set of guiding principles:

- Fast: Speed is not everything, but it is important. With the pace of change accelerating, policy-makers must recognize that the process of making rules and setting standards must keep up with technological shifts.

- Agile: Governance bodies and committees, regulators and policy-makers must have the flexibility to respond rapidly to changing circumstances without losing sight of the overarching goals and values the legislation is designed to support. As technologies evolve, regulators must have the ability to correct their course in real-time.

- Experimental and iterative: Part of adopting a more agile and flexible approach to policy-making is the need to be both more experimental and more iterative. Rather than running long, time-consuming processes for setting rules and standards, policy-makers will need to develop ideas quickly, implement these ideas in experimental settings, learn lessons quickly and steer this feedback into the rule-making process. Building institutions that can link local-scale experiments in different countries could provide a faster way of designing regional regulations. In some cases, this suggests a bottom-up approach to the design of regional regulation.

- Inclusive and multistakeholder: Truly effective policy-making must consider the views and input of all stakeholders. For example, formulating policy on self-driving cars will require inputs not only from governments and automobile companies but also from insurers, urban planners, consumer groups, ethics advisers, technology firms and environmental experts.
- Open: The Fourth Industrial Revolution is a global phenomenon and regional-level approaches should not close doors to wider collaboration. ASEAN's historical approach to open regionalism makes it an ideal platform for enabling the development of supranational regulations and legislation that can open doors to the global market while maintaining the values and principles of the region. 


\section{A way forward for ASEAN: Suggestions for ASEAN leaders to consider}

Having set out the urgency for ASEAN leaders to consider a new approach to regional integration under the Fourth Industrial Revolution, this paper concludes with a set of suggestions that might offer a way forward.

These suggestions do not focus on specific policies themselves (such as how to deepen internet access or how to address data protection). Rather they focus on the process by which policies are designed and developed. They focus on the overarching system of governance and how to ensure that the ASEAN organization, as the body driving regional governance, can be agile, fast, iterative, experimental, inclusive and open.

Of critical importance, any suggestions for reforming the ASEAN organization must not lose sight of the strengths of the ASEAN Way. As mentioned earlier, this approach to regional governance has served South-East Asia well for the past 50 years.

Yet, at the same time, the ASEAN Way may need an upgrade in the era of the Fourth Industrial Revolution. Already it is apparent that the region is struggling to achieve the goals set out under the vision of the AEC. And navigating the new era will place much heavier demands on the region. So, while respecting the strengths of the ASEAN Way, what can the region do to upgrade its approach to regional governance?

\section{ASEAN Secretariat to become a "platform organization"}

Regional integration, particularly in the era of the Fourth Industrial Revolution, is highly complex. Every industry standard, every investment rule, every technical agreement that is addressed requires not only significant expertise but also considerable time and effort. Overseeing this complexity, and doing it at the speed of the Fourth Industrial Revolution, demands a new approach to organizing regional integration efforts.

One important idea is for the ASEAN Secretariat to consider becoming more of a "platform organization". This means creating an ecosystem upon which multistakeholder groups of experts do the heavy lifting of integration, with the Secretariat acting as the convener and governor of their activities.
A useful analogy is the Apple iOS or Android operating systems used on smartphones. In both cases, Apple and Google create the ecosystem upon which third parties software developers - are the main actors. Neither Apple nor Google are directly involved in developing new apps. Instead, their role is to govern the ecosystem and to make sure that it runs smoothly, with all actors adhering to the rules of the platform. (In this case, the rules would cover things such as the technical standards that developers must follow for their apps to work.)

In the context of ASEAN, the Secretariat would design and run the "operating system for regional integration". Third parties - multistakeholder groups of experts - would do the work of designing and formulating new standards, policies and regulations for integration. The role of the Secretariat would be to ensure that all the various integration projects running on its "operating system" are well governed and are conducted in the right manner. (In this case, the rules would cover things such as the composition of working groups and the processes by which they develop policy proposals.)

In many senses, the ASEAN Secretariat already functions as a platform organization. But the idea would be to formalize and upgrade the operating system so that the "app developers" (the multistakeholder groups working on integration projects) could function more effectively. For the Secretariat, this would mean a shift in how it works. On the one hand, it would play a stronger role in running the "operating system for regional integration", through things such as convening and governing working groups. On the other hand, it would play a reduced role in producing the actual content of integration (the suggestions for new standards and regulations), which would be produced by the working groups.

Staff at the ASEAN Secretariat would not be experts themselves on the details of standards or regulations. Instead, they would be experts on running and administering the operating system for integration.

Ideas for developing new "apps" or integration projects would need to be endorsed by the ASEAN member states. But, once endorsed, a working group would be convened on the platform to do the work of crafting the regulations. The ASEAN Secretariat would oversee the formation of the working group and ensure that the group followed agreed processes for developing regulations. For example, a proposal might be submitted to the Secretariat to develop a set of rules governing data privacy. Once approved by the 
ASEAN leaders, a working group would be convened of national regulators, technology companies, academics and civil society leaders. This working group would follow the procedures set out by the Secretariat to produce a mutually agreed set of rules to be implemented at a regional scale.

This platform model is not intended in any way to undermine the sovereignty of ASEAN nations. Any proposals for new regulations or standards would still need to be ratified at a national level before they became law.

In developing this "platform" concept, the Secretariat could look to the example of the OECD, an intergovernmental organization with 35 members. It brings together various stakeholders from government, business, civil society and other groups to work collectively on important issues. Sometimes this work results in the creation of standards, such as on the safety of chemicals, or on tax. The process of creating these standards is driven by consensus and the output is in no way legally binding on the member governments unless they decide to implement it at a national level. However, the simple process of identifying best practice approaches towards regulations does create a "soft law" effect, whereby expectations rise that suggestions from the OECD should be implemented by governments.

Adopting a platform approach would require significant changes to the modus operandi of the Secretariat. As such, it would make sense to adopt a stepped approach, whereby certain regulatory issues, such as those governing e-payments, are experimented with first adopting a "sandbox" approach. If the model is proven to be effective, the approach could be adopted more broadly.

\section{Delegate key activities to affiliated functional bodies}

Extending the idea of ASEAN as a platform organization, the Secretariat could also consider delegating more functions to affiliated third-party groups. These groups or institutions would operate on the platform in a more independent fashion. This would allow ASEAN to maintain oversight while also benefiting from a larger ecosystem of institutions, which will be critical in managing the sheer scale of engagement and implementation that will be required. To date, ASEAN has been reluctant to delegate many of its functions, but there are examples that have worked well.

One notable example is the ASEAN Macroeconomic Research Office (AMRO), which is responsible for managing the region's financial safety net under the Chiang Mai Initiative Multilateralization. Another good example comes from the ASEAN Infrastructure Fund, which provides a platform for public-private partnerships (PPPS) in investments required under the ASEAN Connectivity Masterplan ${ }^{21}$. Again, ASEAN has delegated responsibility for this fund to other experts - in this case, the management and administration of the fund is carried out by the Asian Development Bank on behalf of the ASEAN organization.

\section{Shift from long-term blueprints to rolling three-year plans}

At present, ASEAN invests considerable effort in developing a strong long-term vision for regional integration with documents such as the ASEAN Economic Community Blueprint 2025. Arguably, however, because the Fourth Industrial Revolution is characterized by rapid, non-linear change, plans such as these quickly become outdated. Under the Fourth Industrial Revolution it is advisable not to attempt to forecast the future because most forecasts are likely to be wrong. Rather, it is important to be agile and allow for course correction. ASEAN could, therefore, consider supporting its overarching goals with rolling threeyear strategies that are revisited and revised frequently.

\section{Ask the people: Democratize and decentralize}

If ASEAN is truly to benefit from the widespread expertise in its societies, it should consider increasing its openness to their direct engagement in policy creation. The founding vision of ASEAN was to create an organization that is owned by the people of ASEAN and run for their benefit ${ }^{22}$. The Fourth Industrial Revolution could help this vision to become reality.

As internet and smartphone penetration deepens across ASEAN, there is substantial opportunity to make ASEAN policy formulation more inclusive. Dedicated portals could be established to gain direct feedback from citizens and experts. Policies could be debated in public. Ideas could be crowdsourced. By embracing new Fourth Industrial Revolution tools for public engagement, a more democratized and decentralized vision for the ASEAN organization could emerge.

\section{Multi-country test beds}

A pan-ASEAN platform could be established that would nurture multi-country regulatory experiments and crossborder innovation hubs. An initiative of this kind was set up in Europe in March 2017, called the European Platform of National Initiatives (EPNI). The goal of EPNI is to help European industries respond and stay abreast of the Fourth Industrial Revolution by linking national initiatives to create multi-country test beds and "sandboxes" where regulations can be tested in different regulatory contexts to help a rapid roll-out across the wider European Union. EPNI is multistakeholder in character, bringing together business leaders, regulators, academics and others to work collectively on crafting new regulatory approaches to digital technologies. Currently, 13 national initiatives have joined forces under the EPNI and the EU has earmarked $€ 5$ billion of investment to support the initiative, with significantly more investment expected to be raised from the private sector.

\section{A new staffing model for the Secretariat}

Running the "operating system" for regional integration would require the ASEAN Secretariat to think in new ways. The key to success is operational or execution excellence. In particular, the Secretariat would need to hire staff capable of running a platform model effectively and who are wellversed in managing the new tools, such as new systems of 
communication, new mechanisms for virtual collaboration, new tools for gathering feedback and ideas, and for directing feedback into policy discussions.

Alongside a shift in skills, ASEAN leaders could consider a new approach to the recruitment of staff, with workers hired for their skills, based on merit, and hired on a permanent basis. While some positions at the Secretariat are already of this character, the idea of "appointed" positions, based on rotation among ASEAN nations, would be phased out.

In a similar development, the Secretariat could consider appointing a permanent "CEO" type of leader, hired for his or her experience of crafting regulation and policy, and with a strong record of execution.

\section{A new funding model for the Secretariat}

To recruit the right staff, in the right number, and to build the right systems to drive integration, the ASEAN Secretariat will need more funding. The current funding level, of roughly \$20 million a year, is not enough. In 2014, the ADB estimated that, by 2030, the ASEAN Secretariat would need an annual budget of \$220 million to manage the ASEAN Community effectively ${ }^{23}$. This estimate is based on different calculations than would be relevant for the platform model. However, it is clear that sufficient funding for the ASEAN Secretariat as a platform organization would be much larger than at present.

Mahbubani and Sng argue that if contributions by ASEAN member states were calculated according to capacity to pay, ASEAN would be reasonably well funded. For example, if the UN formula for calculating contributions was adopted within ASEAN, an annual budget of \$220 million would require a contribution from Singapore of $\$ 56.78$ million. This contrasts with the budget of Singapore's Defence and Foreign Ministries of $\$ 9.8$ billion and $\$ 353$ million in 2014. Given the role that the ASEAN organization plays in ensuring long-term security and prosperity, this might be money well spent ${ }^{24}$. It is also worth noting that, for specialized vehicles such as the ASEAN Infrastructure Fund, the nations of ASEAN are already practising the principle of making differential contributions, albeit in the form of capital contributions rather than recurrent expenditures.

Naturally, if funding is increased, it creates concerns of a concurrent rise in bureaucracy and waste. These concerns could be addressed by redesigning the ASEAN Secretariat along the lines suggested in this paper, by adopting a platform approach to regional governance and by tweaking the skills of the Secretariat staff. 


\section{Endnotes}

${ }^{1}$ Mahbubani, K and Sng, J. 2017. "The ASEAN Miracle: a Catalyst for Peace”. NUS Press: Ridge Books

2 Hill, H. and Menon, J. 2014. "ASEAN Commercial Policy: A Rare Case of Outward-Looking Regional Integration". ADB Working Paper Series on Regional Economic Integration 144, ADB

${ }^{3}$ Kobayashi, K, Rashid, K, Furuichi, M, and Anderson, W. 2017. "Economic Integration and Regional Development: The ASEAN Economic Community". Routledge Studies in the Modern World Economy

${ }^{4}$ Jack Ma was speaking at an event organized by the China Entrepreneur Club in May 2017 in Zhengzhou, China

5 Schwab, K, 2016. "The Fourth Industrial Revolution". Penguin Group

6 "BCG Technology Advantage", April 2015, Boston Consulting Group

7 OECD Publishing, 2015, "OECD Education at a Glance 2015: OECD Indicators"

${ }^{8}$ ASEAN Secretariat, 2016. "Master Plan on ASEAN Connectivity 2025"

${ }^{9}$ Global Financial Development Indicators on proportion of population (age 15 and above) with an account at a formal financial institution in 2014 (latest available)

${ }^{10}$ AT Kearney and Axiata, 2016 "The ASEAN Digital Revolution"

${ }^{11}$ 56\% in Cambodia and 52\% in Myanmar in 2014

12 Japanese International Cooperation Agency. 2014.

"Roadmap for Transport Infrastructure Development for Metro Manila and Its Surrounding Areas (Region III and Region IV-A)"

${ }^{13}$ Anbumozhi, V and Intal, P, 2015. "Can Thinking Green and Sustainability be an Economic Opportunity for ASEAN?" ERIA Discussion Paper Series

14 Judith Wallenstein and Urvesh Shelat, September 2017. "Learning to love (or live with) the sharing economy", Boston Consulting Group

${ }^{15}$ China's carbon asset market introduced a blockchainbased management platform in May 2017

${ }^{16}$ Chang, J-H and Huynh, P, 2016. "ASEAN in

Transformation: The Future of Jobs at Risk of Automation." International Labour Organization. This is based on analysis of technology impact on the following industries: automotive; electrical; textiles; business process outsourcing, and retail
${ }^{17}$ Based on United Nations Projections of ASEAN's working age population growing by 62 million between 2015 and 2030.

${ }^{18}$ Based on current US\$ GDP accessed from World Bank Databank

${ }^{19}$ Center for Strategic \& International Studies, June 2014. "Net Losses: Estimating the Global Cost of Cybercrime"

20 Batalova, J, Shymonyak, A, and Sugiyarto, G. 2017.

"Firing Up Regional Brain Networks: The Promise of Brain Circulation in the ASEAN Economic Community"

${ }^{21}$ ASEAN Secretariat. 2016. "Master Plan on ASEAN Connectivity 2025"

22 The Association of South-east Asian Nations, July 2017 "The ASEAN Charter - 21st Reprint"

${ }^{23}$ Asian Development Bank Institute. 2014. "ASEAN 2030: Towards a Borderless Economic Community"

${ }^{24}$ Mahbubani, K and Sng, J. 2017. "The ASEAN Miracle: a Catalyst for Peace". NUS Press: Ridge Books 



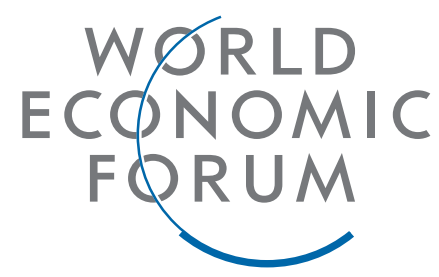

COMMITTED TO

IMPROVING THE STATE

OF THE WORLD

The World Economic Forum, committed to improving the state of the world, is the International Organization for Public-Private Cooperation.

The Forum engages the foremost political, business and other leaders of society to shape global, regional and industry agendas. 